\title{
Silibinin downregulates MMP2 expression via Jak2/STAT3 pathway and inhibits the migration and invasive potential in MDA-MB-231 cells
}

\author{
HYO JOO BYUN $^{1}$, PRAMOD DARVIN ${ }^{1}$, DONG YOUNG KANG ${ }^{1}$, NIPIN SP ${ }^{1}$, \\ YOUN HEE JOUNG ${ }^{1}$, JONG HWAN PARK ${ }^{1}$, SUN JIN KIM ${ }^{2}$ and YOUNG MOK YANG ${ }^{1}$ \\ ${ }^{1}$ Department of Pathology, School of Medicine, Institute of Biomedical Science and Technology, \\ Konkuk University, Chungju 27478, Republic of Korea; ${ }^{2}$ Trinity Court, Cardiff CF24 0AA, Wales, UK
}

Received October 21, 2016; Accepted April 3, 2017

DOI: $10.3892 /$ or.2017.5588

\begin{abstract}
Worldwide, breast cancer (BCa) is the most common cancer in women. Among its subtypes, triple-negative breast cancer (TNBC) is an aggressive form associated with diminished survival. TNBCs are characterized by their absence, or minimal expression, of the estrogen and progesterone receptors, as well as the human epidermal growth factor receptor 2 (i.e. $\left.\mathrm{ER}^{-/}, \mathrm{PR}^{-/}, \mathrm{Her} 2^{-/ \mathrm{Low}}\right)$. Consequently, treatment for this subtype of BCa remains problematic. Silibinin, a derivative of the flavonoid silymarin, is reported to have anticancer activities against hepatic and non-small cell lung cancers. We hypothesized that silibinin might inhibit cell-extracellular matrix interactions via the regulation, expression, and activation of STAT3 in TNBCs, which could directly inhibit metastasis in silibinin-treated $\mathrm{BCa}$ cells. Using proliferation assays, we found that exposure to silibinin at a concentration of $200 \mu \mathrm{M}$ inhibited the proliferation of breast cancer (BCa) cells; this concentration also inhibited phosphorylation of STAT3 and its principal upstream kinase, Jak2. Furthermore, we found that silibinin inhibited the nuclear translocation of STAT3, as well as its binding to the $M M P 2$ gene promoter. The ability of silibinin to inhibit metastasis was further studied using an in vitro invasion assay. The results confirm the role of STAT3 as a critical mediator in the invasive potential of $\mathrm{BCa}$ cells, and STAT3 knock-down resulted in inhibition of invasion. The invasion ability of silibinin-treated BCa cells was studied in detail with the expression of MMP2. Prevention of STAT3 activation also resulted in the inhibition of MMP2 expression. Use of a small interfering RNA to knock down STAT3 (siSTAT3) allowed us to confirm the role of STAT3 in regu-
\end{abstract}

Correspondence to: Dr Young Mok Yang, Department of Pathology, School of Medicine, Institute of Biomedical Science and Technology, Konkuk University, Chungju 27478, Republic of Korea

E-mail: ymyang@kku.ac.kr

Key words: Jak2/STAT3, MMP2, silibinin, breast cancer, triplenegative breast cancer cell, invasion, metastasis lating MMP2 expression, as well as the mechanism of action of silibinin in inhibiting MMP2. Taken together, we found that silibinin inhibits the Jak2/STAT3/MMP2 signaling pathway, and inhibits the proliferation, migration, and invasion of triplenegative BCa cells.

\section{Introduction}

Globally, breast cancer (BCa) is the most prevalent form of cancer among women (1). In particular, the basal form of cancer carrying the triple-negative (TNBC) phenotype comprises $10-15 \%$ of all forms of $\mathrm{BCa}$, and manifests the worst prognosis and morbidity (2). TNBC demonstrates aggressive proliferation and metastasis. Given its lack of the endocrine receptors for estrogen, progesterone [estrogen receptor (ER), and progesterone receptor (PR)], and the human epidermal growth factor receptor-2 (HER-2), targeted therapy for this form of cancer remains a challenge (3). These cancer types express a high concentration of epidermal growth factor receptor (EGFR). Disappointingly, while targeted therapies against the EGFR have demonstrated a promising reduction in the tumor mass, overall survival rate has remained unchanged. Consequently, there is considerable impetus to investigate agents such as phytochemicals and their potential to target TNBCs and inhibit tumor progression and metastasis.

Signal transducers and activators of transcription (STAT) constitute a family of seven transcription factors, STAT1, STAT2, STAT3, STAT4, STAT5a, STAT5b, and STAT6. STATs are overexpressed in a variety of cancers including breast cancer, head and neck cancer, and hematologic malignancies $(4,5)$. Among the members of STAT family, STAT3 and STAT5b play significant roles in the initiation, progression, and spread of malignant breast tumors, and are termed oncogenes (6). STAT3 has been found to have strong association with migration, invasion, and the metastatic capacity of cells. Multiple genes involved in complex metastatic networks are regulated by STAT3, making it a valuable target for the inhibition of metastasis. The activation of STAT proteins is mediated via the ligand associated tyrosine kinase, Janus kinase (Jak), in particular, Jak-2 (7). Upon phosphorylation of specific residues in STATs, homo- or heterodimer formation 
ensues, followed by nuclear translocation. Once in the nucleus, activated STAT molecules bind to specific response elements in target gene promoters to transcriptionally activate them (8). Not surprisingly, the role of Jak2/STAT3 pathway in cell proliferation, differentiation, apoptosis, and metastasis, has been the subject of intense investigation $(9,10)$.

Matrix metalloproteinases (MMPs) are a group of proteins responsible for the degradation of the extracellular matrix (ECM), and play a major role in cancer progression by their impact on invasion, migration, and the metastasis of cancerous cells (11). The control of MMP activity is, potentially, a potent tool with which to prevent cancer metastasis (12). MMPs are mainly divided into six categories: the collagenase group, gelatinase group, stromelysin group, matrilysin group, membrane-type MMPs, and others (13). MMP2 is a member of gelatinases group, which has been studied in various aspects of cancer progression (14), including migration, invasion, and metastasis. In endothelial cells, $M M P 2$ is found to increase angiogenesis by digesting the extracellular membrane $(15,16)$ following chemokine stimulation. Xie et al have reported that STAT3 activation-regulates brain tumor metastasis via MMP2 (17), and suggested that MMP2 is a downstream target of STAT3 $(17,18)$. Furthermore, Lee et al suggest that the status of STAT3 controls the expression and secretion of MMP2 (19). These data led us to hypothesize that the inhibition of STAT3 activation, and therefore MMP2, could be exploited in TNBC cells in order to inhibit their metastatic phenotype.

Silibinin is the primary active component of the flavonoid silymarin, and is extracted from milk thistle seeds $(20,21)$. In the US and in Eastern European countries, silibinin is used as a drug for toxic liver damage, chronic hepatitis, and cirrhosis (22). However, recent studies show that silibinin is a powerful antioxidant and scavenger, capable of reducing lipid peroxidation $(23,24)$, with promise as a cancer cell growth inhibitor, cell cycle regulator, and apoptosis inducer in prostate and colon carcinoma cells $(25,26)$. In particular, Bosch-Barrera and Menendez have reported the importance of STAT3 in regulating tumor growth, highlighting the potential of silibinin as a novel clinical approach with which to inhibit Jak2/STAT3 pathway and related effectors in breast, colon, prostate, and lung cancers (27). Furthermore, silibinin pretreatment confers a favorable effect on the phosphorylation of STAT3, as well as the expression of MMP2 (28).

In the present study, we focused on the modulation of Jak2/STAT3 pathway using silibinin, and its inhibition of in vitro metastasis by diminishing MMP2 expression and activity in TNBC cells. We found that silibinin has an anti-proliferative effect on TNBC cells, and inhibits their invasive as well as migratory abilities by downregulating MMP2 gene expression, following inhibition of the JAK2/STAT3 signaling pathway in TNBC cells.

\section{Materials and methods}

Antibodies and cell culture reagents. Dulbecco's modified Eagle's medium (DMEM) was purchased from Sigma Chemical Co. (St. Louis, MO, USA). Penicillin-streptomycin solution and fetal bovine serum (FBS) were purchased from Hyclone (South Logan, UT, USA). Trypsin-EDTA (0.05\%) was obtained from Gibco-BRL (Grand Island, NY, USA).
Antibodies specific for phosphorylated STAT3 (Tyr705), STAT3, MMP9, and $\beta$-actin, together with secondary antibody reagents (goat anti-mouse and rabbit IgG-horseradish peroxidase), were obtained from Santa Cruz Biotechnology (Santa Cruz, CA, USA). Antibodies against MMP2 were purchased from Enogene Biotech Co. (NY, USA), with an anti-Jak2 antibody obtained from Millipore (Billerica, MA, USA). An anti phosphor Jak2 antibody (Tyrosine residue 1007/1008) was purchased from Cell Signaling Technology (Beverly, MA, USA). Silibinin was purchased from Sigma Co. (diluted in DMSO).

Cell culture and drug treatments. MDA-MB-231 human breast cancer cells were cultured in DMEM containing 10\% FBS, $2 \mathrm{mM}$ glutamine, and $100 \mathrm{U} / \mathrm{ml}$ penicillin and streptomycin. Cell culture was at $37^{\circ} \mathrm{C}$, in a $5 \% \mathrm{CO}_{2}$ gassed incubator. For each experiment, cells were resuspended in medium at a density of $2.5 \times 10^{5}$ cells $/ \mathrm{ml}$. Unless otherwise specified, cells were treated with $200 \mu \mathrm{M}$ silibinin for $24 \mathrm{~h}$.

Inhibition of cell proliferation. Cell viability was assayed by MTT assay. Briefly, cells were resuspended in DMEM one day before drug treatment, at a density of $3 \times 10^{3}$ cells per well in 96-well culture plates. Culture medium was replaced with fresh medium containing dimethyl sulfoxide (DMSO) as a vehicle control. Cells were incubated with increasing concentrations of silibinin (from 50 to $350 \mu \mathrm{M}$ ). Following drug treatment, MTT $(5 \mathrm{mg} / \mathrm{ml})$ was added, with culture dishes incubated for $4 \mathrm{~h}$ at $37^{\circ} \mathrm{C}$. The resulting formazan product was dissolved in DMSO and its absorbance read at $550 \mathrm{~nm}$ on an Ultra Multifunctional Microplate Reader (Tecan, Durham, NC, USA). All measurements were performed in triplicate, with experiments repeated at least three times.

Western blotting. Whole cell lysates from MDA-MB-231 cells treated (or not) with silibinin were prepared on ice using radioimmunoprecipitation (RIPA) lysis buffer containing phosphatase and protease inhibitors. Cells were disrupted by aspiration through a 23 -gauge needle and centrifuged at $15,000 \mathrm{rpm}$ for $10 \mathrm{~min}$ at $4^{\circ} \mathrm{C}$ to remove cellular debris. Protein concentrations were measured using the Bradford method (Thermo Fisher Scientific, MA, USA). Equal amounts of protein were resolved by sodium dodecyl sulfate-polyacrylamide gel electrophoresis (SDS-PAGE) and then transferred onto nitrocellulose membranes. The blots were blocked for $1 \mathrm{~h}$ with 5\% skimmed milk in TBS-T buffer. Membranes were then probed overnight at $4^{\circ} \mathrm{C}$ with the relevant primary antibody, followed by washing with TBS-T and incubated for $1 \mathrm{~h}$ with the horseradish peroxidase-conjugated secondary antibodies. Detection was performed using the ECL Plus detection kit [Amersham Pharmacia Biotech (Piscataway, NJ, USA)] and a LAS-4000 imaging device (Fujifilm, Japan). Blot stripping was with Restore western blot stripping buffer.

Reverse transcription-polymerase chain reaction (RT-PCR). Total RNA was extracted using the RNeasy Mini kit and QIAprep Spin Miniprep kit (Qiagen) according to the manufacturer's protocol,withRNAquantified spectrophotometrically at $260 \mathrm{~nm}$. Then, RT-PCR analyses for $M M P 2, M M P 9$, and $18 S$ RNA were performed. cDNA was synthesized from total 
RNA using a first strand cDNA synthesis kit (Bioneer, Korea) and oligo d(T) primers. The RT-PCR Premix kit with primers for MMP2, MMP9, and 18S amplification, were synthesized by Bioneer (Daejeon, Korea). PCR amplification to generate a 472-bp $M M P 2$ fragment was with the following primers: $M M P 2$ sense, 5'-GGCCCTGTCACTCCTGAGAT-3'; antisense, 5'-GGCATCCAGGTTATCGGGGA-3'. The PCR conditions were $94^{\circ} \mathrm{C}$ for $5 \mathrm{~min}$, and then 32 cycles of $94^{\circ} \mathrm{C}$ for $30 \mathrm{sec}, 58^{\circ} \mathrm{C}$ for $30 \mathrm{sec}, 72^{\circ} \mathrm{C}$ for $45 \mathrm{sec}$, followed by $72^{\circ} \mathrm{C}$ for $7 \mathrm{~min}$. PCR amplification to generate a 455-bp $M M P 9$ fragment involved the following primers and PCR conditions: $M M P 9$ sense, 5'-CCTGCCAGTTTCCATTCATC-3'; antisense, 5'-GCC ATTCACGTCGTCCTTAT- 3 ', $94^{\circ} \mathrm{C}$ for $5 \mathrm{~min}$, and then 30 cycles of $94^{\circ} \mathrm{C}$ for $40 \mathrm{sec}, 60^{\circ} \mathrm{C}$ for $40 \mathrm{sec}, 68^{\circ} \mathrm{C}$ for $50 \mathrm{sec}$, followed by $72^{\circ} \mathrm{C}$ for $7 \mathrm{~min}$. Finally, a 489 -bp amplified $18 S$ mRNA fragment was generated using the following primers and PCR conditions: $18 S$ sense, 5'-CGGCTACCACATCCA AGGAA-3' and antisense, 5'-CCGGCGTCCCTCTTAATC-3', $94^{\circ} \mathrm{C}$ for $5 \mathrm{~min}$, and then 30 cycles of $94^{\circ} \mathrm{C}$ for $40 \mathrm{sec}, 60^{\circ} \mathrm{C}$ for $40 \mathrm{sec}$, and $68^{\circ} \mathrm{C}$ for $50 \mathrm{sec}$, followed by $72^{\circ} \mathrm{C}$ for $7 \mathrm{~min}$. PCR products were resolved by electrophoresis on a $1 \%$ agarose gel with PCR products visualized by ethidium bromide staining.

Electrophoretic mobility shift assay (EMSA). STAT3 DNA binding activity was detected using EMSA (Promega Corp., Madison, WI, USA). The electrophoretic mobility shift assay (EMSA) kit, oligonucleotide probes (STAT3), and reporter lysis buffer were from Promega. MDA-MB-231 cells were grown to $\sim 90 \%$ confluence with nuclear protein extracts prepared using the Nuclear Extract kit (Affymetrix, CA, USA). EMSA was performed using the EMSA gel shift kit (Panomics, Fremont, CA, USA), according to the manufacturer's protocol. Briefly, nuclear protein was subject to hybridization to a double stranded, biotin-labeled oligonucleotide probe, containing the consensus-binding site for STAT3 (sense strand, 5'-GATCCTT CTGGGAATTCCTAGATC-3'). The protein-DNA complexes were resolved on a 6\% non-denaturing PAGE gel and then transferred to a Pall Biodyne B nylon membrane (Pall Life Sciences, Pensacola, FL, USA). Signal detection was with streptavidin-HRP and a chemiluminescent substrate.

Small interfering RNA (siRNA) analyses. MDA-MB-231 cells $\left(1 \times 10^{5}\right)$ were cultured in 6-well plates, and grown to $70 \%$ confluence. Cells were then transfected with the ON-TARGETplus SMARTpool siRNA, targeting STAT3, or ON-TARGETplus non-target siRNA (Dharmacon, Chicago, IL, USA), as a control. Transfection was with the DharmaFECT transfection reagent (Dharmacon, Lafayette, CO, USA), according to the manufacturer's instructions. Following transfection for $48 \mathrm{~h}$, cells were cultured in serum-free medium for a further $24 \mathrm{~h}$, and then exposed to $200 \mu \mathrm{M}$ silibinin for $24 \mathrm{~h}$. Levels of STAT3, p-STAT3, MMP2, and $\beta$-actin were quantified by western blotting.

Wound healing assay. MDA-MB-231 cells were cultured in 6 -well plates at a concentration of $1 \times 10^{5}$ cells/well in DMEM media (i.e., serum containing), and then incubated for $24 \mathrm{~h}$ in a humidified chamber. After forming a confluent monolayer, the cell layer was scratched with a pipette tip and washed with PBS to remove cell debris. Cells were untreated (controls) or

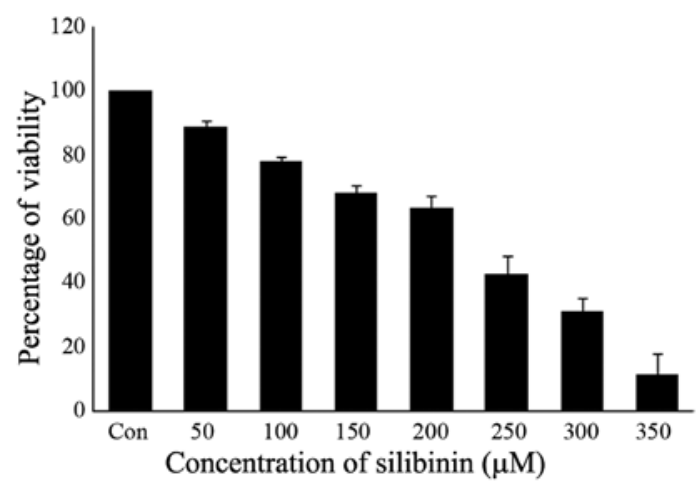

Figure 1. Silibinin inhibits the viability of MDA-MB-231 breast cancer cells in a dose-dependent manner. MDA-MB-231 cells were exposed to silibinin for $24 \mathrm{~h}$, with cell viability evaluated using the MTT assay. A 50\% inhibition of cell proliferation was incurred at a concentration of $200 \mu \mathrm{M}$ silibinin, which was subsequently adopted as the $\mathrm{IC}_{50}$ dosage.

exposed to 100 or $200 \mu \mathrm{M}$ silibinin. Images of the scratch sites (wounds) were captured at 0 and $24 \mathrm{~h}$, and the average area of the wound calculated using ImageJ software.

Matrigel invasion assay. The Transwell invasion assay was performed using Matrigel pre-coated, ready to use invasion chambers (BD Biocoat, MA, USA). Cells suspended at 5x10 were added to the inserts. Drug-containing media was then added to the receiver plate, and the inserts placed onto it. After a 24-h incubation in a humidified chamber at $37^{\circ} \mathrm{C}$, the cells that had invaded the apical surface of the inserts were identified using crystal violet. The plates were then incubated in ambient conditions for $24 \mathrm{~h}$ followed by a wash and then fixation using formaldehyde. The cells on the upper surface were removed using a cotton swab and the invaded cells quantified using a microscope. Cells were counted in four fields of view.

Statistical analyses. All experiments were performed at least three times with results expressed as means \pm SEM. Statistical analyses were with ANOVA and Student's t-test (SAS 9.3 program). One-way analysis of variance (ANOVA) was performed with Duncan's multiple range test. A p-value of $<0.05$ was considered to be statistically significant.

\section{Results}

Silibinin inhibits MDA-MB-231 cell proliferation. The effect of silibinin on cell proliferation was examined by the MTT assay. The human triple-negative breast cancer cell line MDA-MB-231 was exposed to increasing concentrations of silibinin $(50,100,150,200,250,300$ and $350 \mu \mathrm{M})$ for a period of $24 \mathrm{~h}$. The number of silibinin-treated cells during the logarithmic phase of growth was compared to that of control cells. Exposure to silibinin substantially decreased viability in a dose-dependent manner, with $\mathrm{IC}_{50}$ values ranging from 200 to $250 \mu \mathrm{M}$ following a 24-h exposure (Fig. 1). Therefore, a $200 \mu \mathrm{M}$ concentration of silibinin was taken as the $\mathrm{IC}_{50}$, with this concentration used in subsequent experiments.

Silibinin suppresses the expression and phosphorylation of Jak2 and STAT3 proteins in a dose and time-dependent 
A

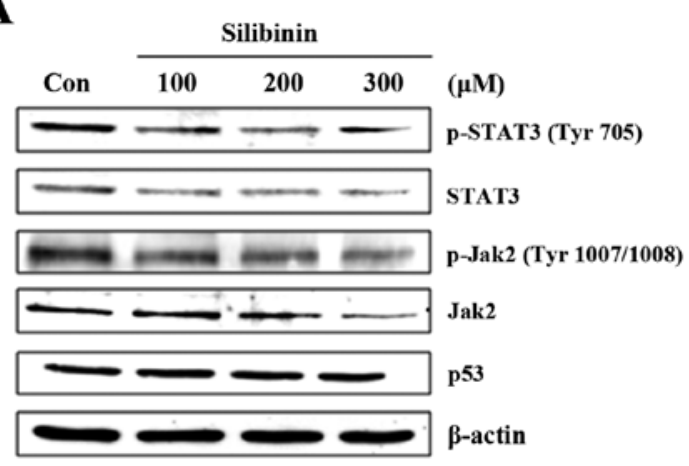

B

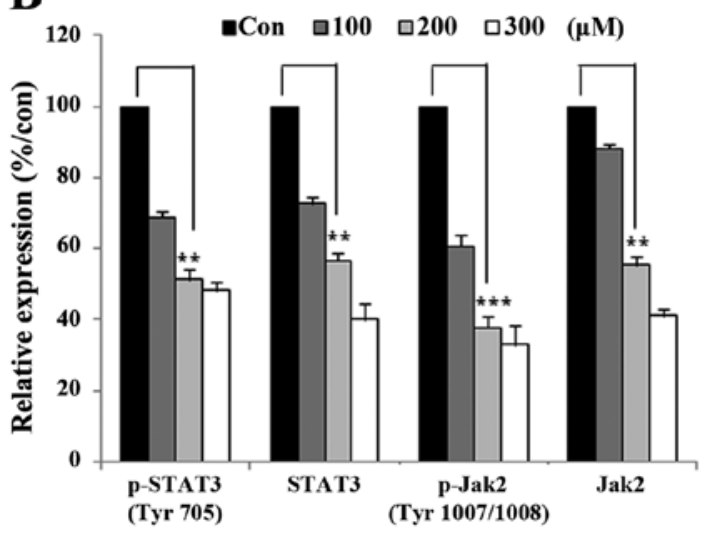

C

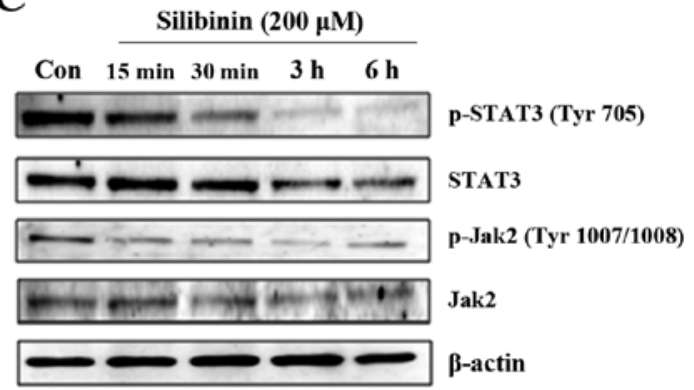

D

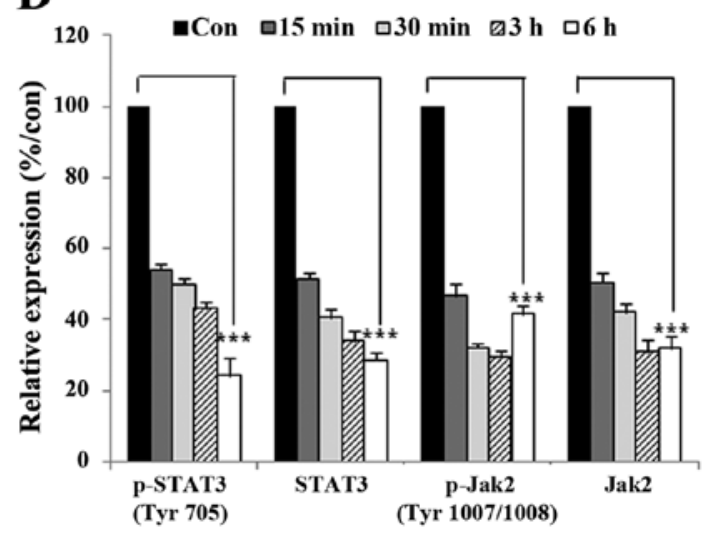

Figure 2. Silibinin downregulates the expression of Jak2/STAT3 signaling proteins in a dose- and time-dependent manner. (A) Western blot analyses showing the concentration dependent effect of silibinin in MDA-MB-231 cells following exposure to silibinin for $24 \mathrm{~h}$. (B) Relative levels of the pSTAT3, STAT3, pJak2, and Jak2 proteins. (C) Time-dependent effect of silibinin on protein expression in MDA-MB-231 cells. (D) Relative expression levels of pSTAT3, STAT3, pJak2, and Jak2, measured using densitometry. These data were normalized to actin levels, and then shown as a percentage of the control. The data presented are representative of three independent experiments. Statistical analyses were conducted using the $\mathrm{t}$-test $\left({ }^{* *} \mathrm{p}<0.01,{ }^{* * * *} \mathrm{p}<0.001\right)$.

manner. We previously reported that STAT3 is a potent signaling molecule associated with tumor development and progression (29). In this study, our aim was to analyze the role of silibinin in the expression of JAK2/STAT3-related proteins. Initially, MDA-MB-231 cells were exposed to silibinin for $24 \mathrm{~h}$ at different doses, and then for varying time periods. Whole cell lysates were prepared using 1X RIPA lysis buffer and immunoblotted using antibodies with Jak2, STAT3, and their respective phospho forms. As seen in Fig. 2A, silibinin suppressed the expression of Jak2, STAT3, and phospho proteins in a dose-dependent manner. Compared with the control group, $200 \mu \mathrm{M}$ silibinin provoked an almost $50 \%$ reduction in the expression of these proteins (Fig. 2B). A time course experiment (15 min to $6 \mathrm{~h}$ ) showed that the expression of STAT3 and phospho proteins continuously decreased in a time-dependent manner. Concurrent with the dose-dependent inhibition experiments, the time-dependent analysis also showed a $50 \%$ reduction in the expression and phosphorylation of Jak2/STAT3 signaling proteins (Fig. 2D). These data suggest that silibinin has the capacity to regulate the activity of the Jak2/STAT3 signaling pathway.

Silibinin inhibits the binding of STAT3 to the MMP2 gene promoter. Recent studies have shown that STAT3 activation regulates MMP2 expression (18). Upon activation, STAT translocates to the nucleus and binds specific response elements in target gene promoters in order to exert transcriptional control. Therefore we assayed levels of STAT3 and pSTAT3 in nuclear extracts prepared from silibinin-treated and control, nontreated TNBC cells. As shown in Fig. 3A, there was a reduction in the level of STAT3 and pSTAT3 in nuclear extracts derived from the $200 \mu \mathrm{M}$ silibinin-treated groups. We then analyzed the $M M P 2$ gene promoter for the presence of a GAS element, the DNA-binding sequence for the STAT family of transcription factors. Having located this element [in a domain upstream of the transcription start site (TSS) (Fig. 3B)] DNA-binding was then studied using EMSA. These data revealed that exposure to silibinin provokes an inhibition of STAT3-DNA binding (Fig. 3C), indicating that silibinin, via STAT3, transcriptionally regulates $M M P 2$ gene expression.

Silibinin mediates a dose-dependent downregulation of $M M P 2$ and MMP9 expression at both the $m R N A$ and protein levels. In the above section we showed that silibinin suppressed Jak2/STAT3 signaling in a dose- and time-dependent manner, and inhibited STAT3-DNA binding. We hypothesized that the inhibition of STAT3-DNA binding should provoke a downregulation of MMP2 gene expression. In order to confirm this, the expression of STAT3 downstream targets were assayed at both the mRNA (Fig. 4A), and protein levels (Fig. 4C). Transcriptional level analyses revealed that treatment with silibinin led to a dose-dependent decrease in the transcription 


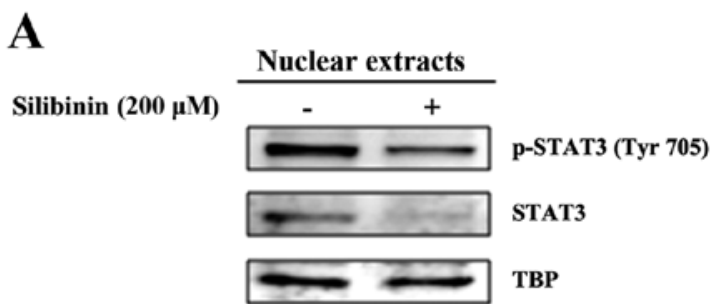

B

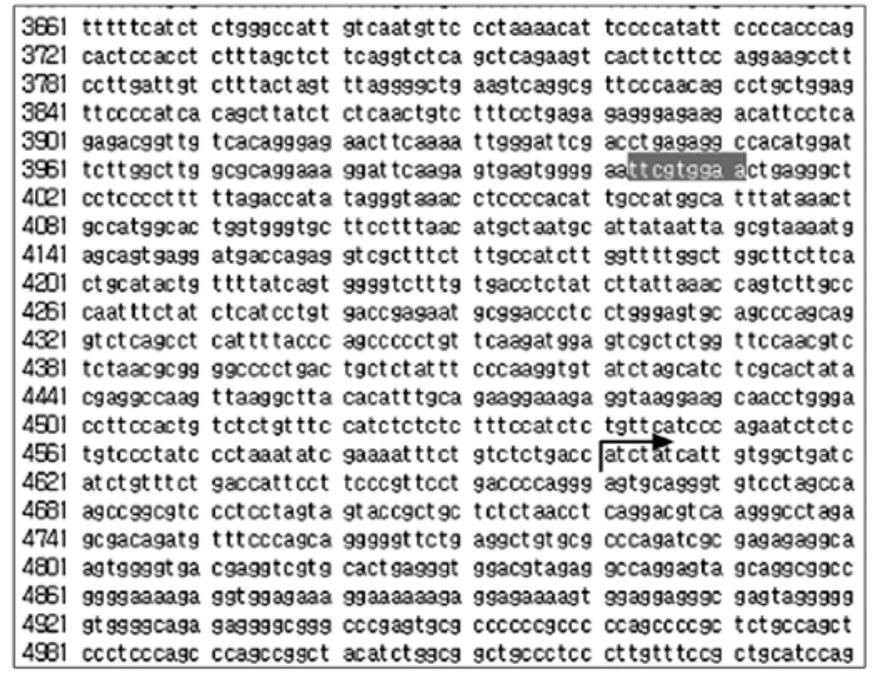
$\longrightarrow$ : TSS (transcription start site)
C

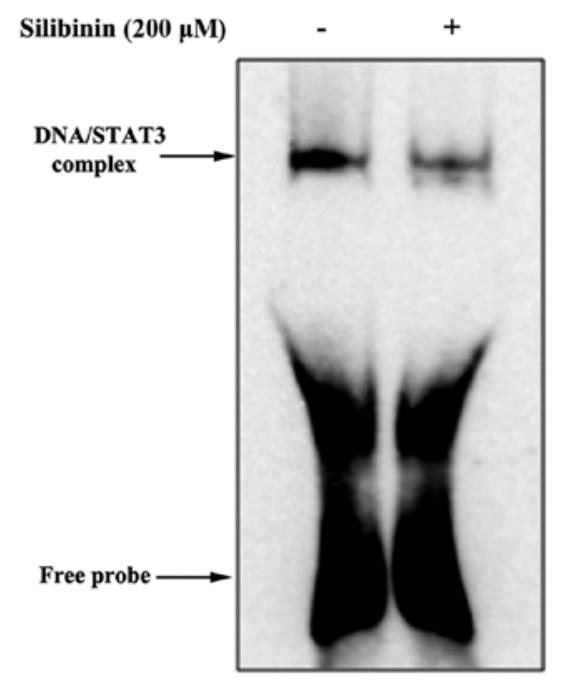

Figure 3. Silibinin inhibits nuclear translocation and the DNA binding activity of STAT3. (A) MDA-MB-231 cells were exposed to $200 \mu \mathrm{M}$ silibinin for $24 \mathrm{~h}$ and nuclear proteins prepared and analyzed by western blotting. Silibinin inhibited the nuclear translocation of STAT3. TBP was used as a loading control. (B) Sequence of the MMP2 gene promoter (http://www.ncbi.nlm.nih.gov/nuccore/212549770) with the GAS element highlighted (nucleotide sequence 4003-4011). (C) The DNA binding activity of STAT3 was inhibited by silibinin, as analyzed by gel shift assay.

A

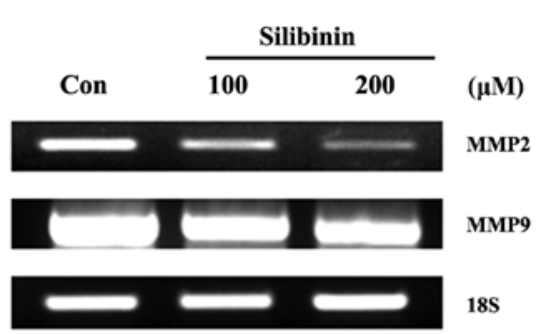

B

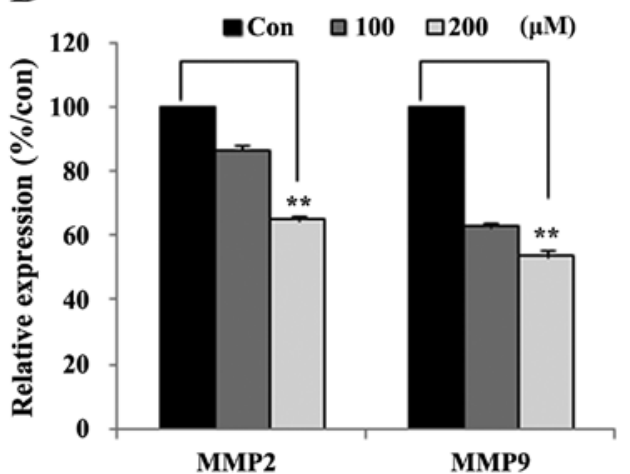

C

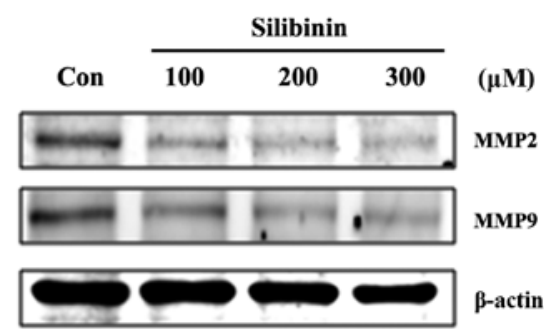

D

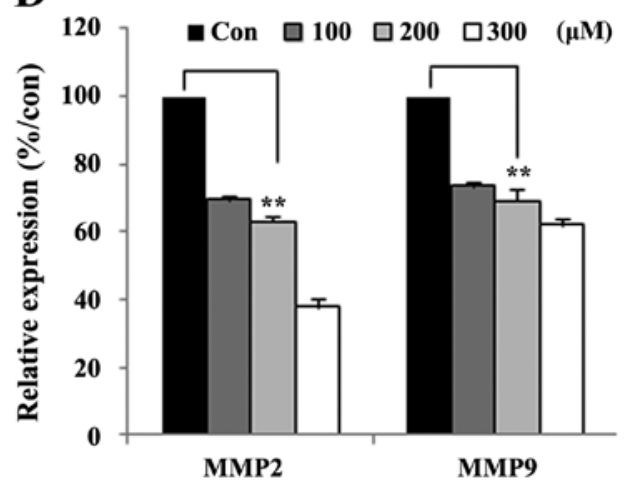

Figure 4. Silibinin downregulates MMP2 and MMP9 expression in MDA-MB-231 cells. (A) Silibinin inhibited the transcription of MMP2 and MMP9 in a dose-dependent manner. 18S mRNA served as the loading control. (B) Relative expression levels of the $M M P 2$ and $M M P 9$ mRNAs as assessed by densitometry. These data were normalized to levels of $18 \mathrm{~S}$, and are shown as a percentage of the control. (C) Western blot analyses showing total protein levels of MMP2 and MMP9 after exposure to silibinin for $24 \mathrm{~h}$. (D) The relative expression levels of MMP2 and MMP9 proteins, normalized to actin, are shown as a percentage of the control. These data are representative of three independent experiments. Statistical analyses were conducted using the t-test $\left({ }^{* *} \mathrm{p}<0.01\right)$. 
A

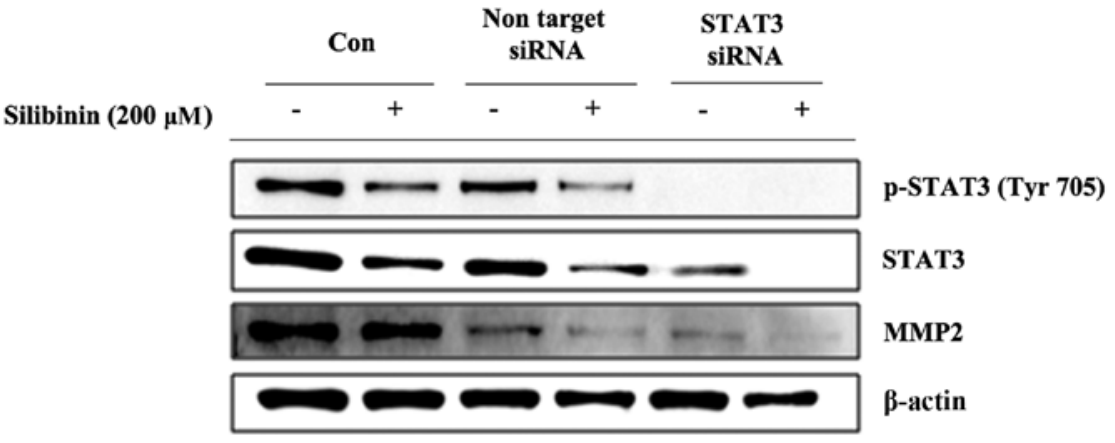

B

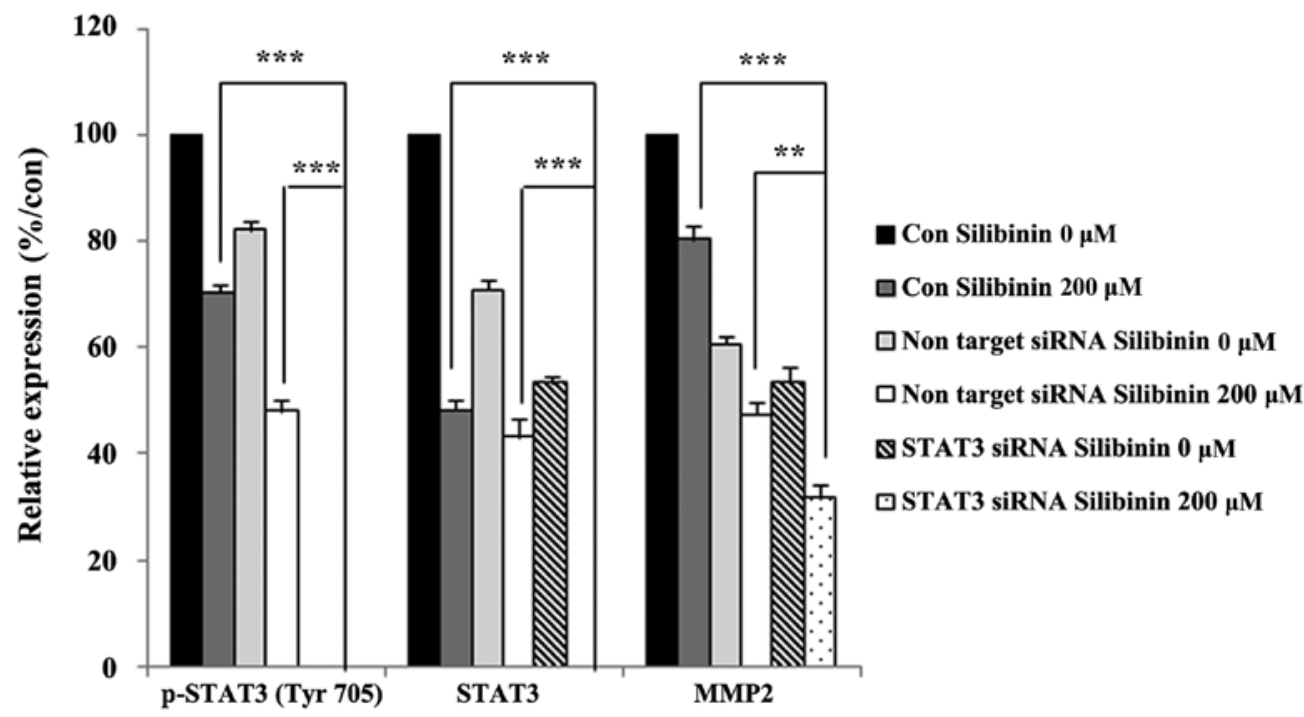

Figure 5. Silibinin inhibits MMP2 expression in a STAT3-dependent manner. STAT3 expression in MDA-MB-231 cells was specifically knocked-down using a siSTAT3 construct; cells were then exposed to silibinin for a period of $24 \mathrm{~h}$. (A) Silibinin inhibited the expression of MMP2 in a STAT3-dependent manner. (B) The relative expression levels of protein were determined and normalized to levels of actin, and are represented as a percentage of the non-treated control. The data shown are representative of three independent experiments. Statistical analyses were conducted using the $\mathrm{t}$-test $\left({ }^{* *} \mathrm{p}<0.01,{ }^{* * * *} \mathrm{p}<0.001\right)$.

of both MMP2 and MMP9 (Fig. 4A). The silibinin-treated groups manifested an $\sim 40-60 \%$ inhibition of MMP2 mRNA expression when compared to non-treated groups (Fig. 4B). Similar to the transcriptional data, at the protein level, dose-dependent reductions in the expression of both MMP2 and MMP9 were evident (Fig. 4C) Membranes were then probed overnight at $4^{\circ} \mathrm{C}$ with the relevant primary antibody, followed by washing with TBS-T and incubated for $1 \mathrm{~h}$ with the horseradish peroxidase-conjugated secondary antibodies with silibinin-treated groups incurring a 40-60\% inhibition of MMP2 protein expression (Fig. 4D).

Silibinin inhibits MMP2 expression via inhibition of STAT3. In order to confirm crosstalk between STAT3 and MMP2 expression, STAT3 was knocked-down using an siSTAT3 construct, and our analyses repeated. STAT3 knock-down cells were exposed (or not, for controls) to silibinin for a predetermined time, then whole cell lysates prepared and analyzed for their expression of MMP2. STAT3 knockdown effectively eliminated STAT3 expression, with levels of MMP2 also markedly reduced (Fig. 5A). The relative expression of protein, with respect to vehicle controls, was performed to confirm the effect of STAT3 on the inhibition of MMP2 expression following exposure to silibinin (Fig. 5B).
These data showed that silibinin could inhibit cell migration and invasion via inhibition of MMP2 in a STAT3-dependent manner.

Silibinin suppresses cell migration and invasion via STAT3 and MMP2. In the previous section we showed that knockdown of STAT3 lead to a decline in the expression of MMP2. MMP2 is a major determinant of cancer invasion, including cell migration and invasion (30). The ability of silibinin to inhibit cancer cell migration was subsequently studied with the help of a wound-healing assay (Fig. 6A). Here the relative inhibition of wound closure was used as a proxy measure for migration. The non-treated control group showed a relatively high degree of cell migration and wound closure, which was diminished in the silibinin-treated group (Fig. 6B). The crossing of the extracellular membrane is an essential step for the dissemination of cancer cells from the primary tumor to distant locations. The ability of silibinin to inhibit this invasion process was studied using a Matrigel invasion assay. Silibinin-treated cells showed a promising inhibition of invasion compared to untreated controls. The role of STAT3 in silibinin inhibition of invasion was then studied using STAT3 knock-down cells. The results confirmed that silibinin and STAT3 play an important role in inhibiting the 
A
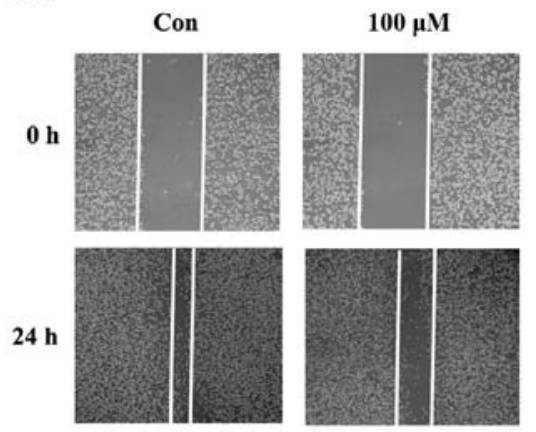

C
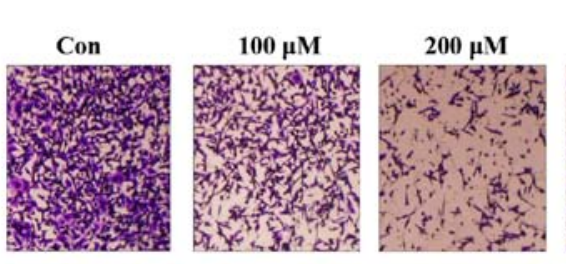
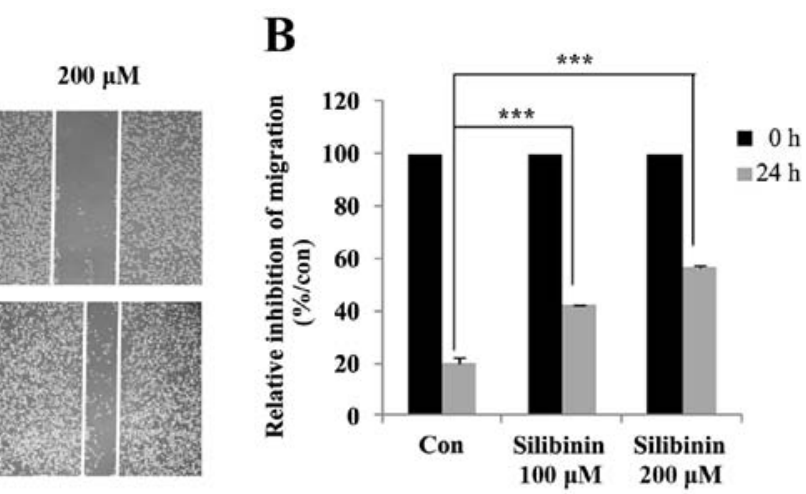

D

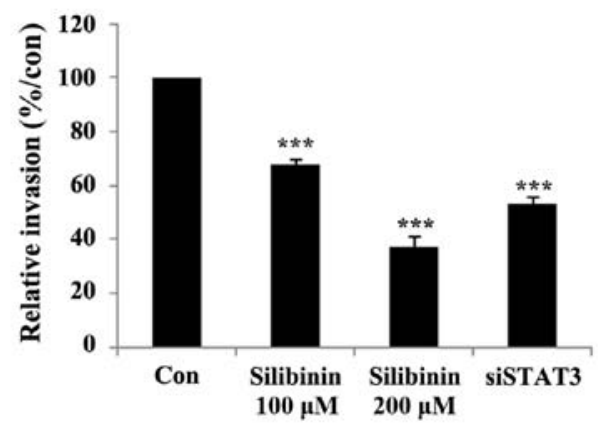

Figure 6. Silibinin inhibits cell migration and invasion via STAT3. (A) A wound healing assay showed a dose-dependent inhibition of migration in MDA-MB-231 cells exposed to silibinin for $24 \mathrm{~h}$. (B) Relative inhibition of migration in MDA-MB-231 cells. Statistical analyses were conducted using the t-tests (**** $<<0.001)$. (C) A Matrigel invasion assay showing the dose-dependent inhibition of invasion in silibinin-treated cells, and in the STAT3 knock-down MDA-MB-231 cells. (D) Relative inhibition of invasion in MDA-MB-231 cells as per the invasion assay. The data presented are representative of three independent experiments. Statistical analyses were conducted using the ANOVA test $\left(^{* * * *} \mathrm{p}<0.001\right)$.

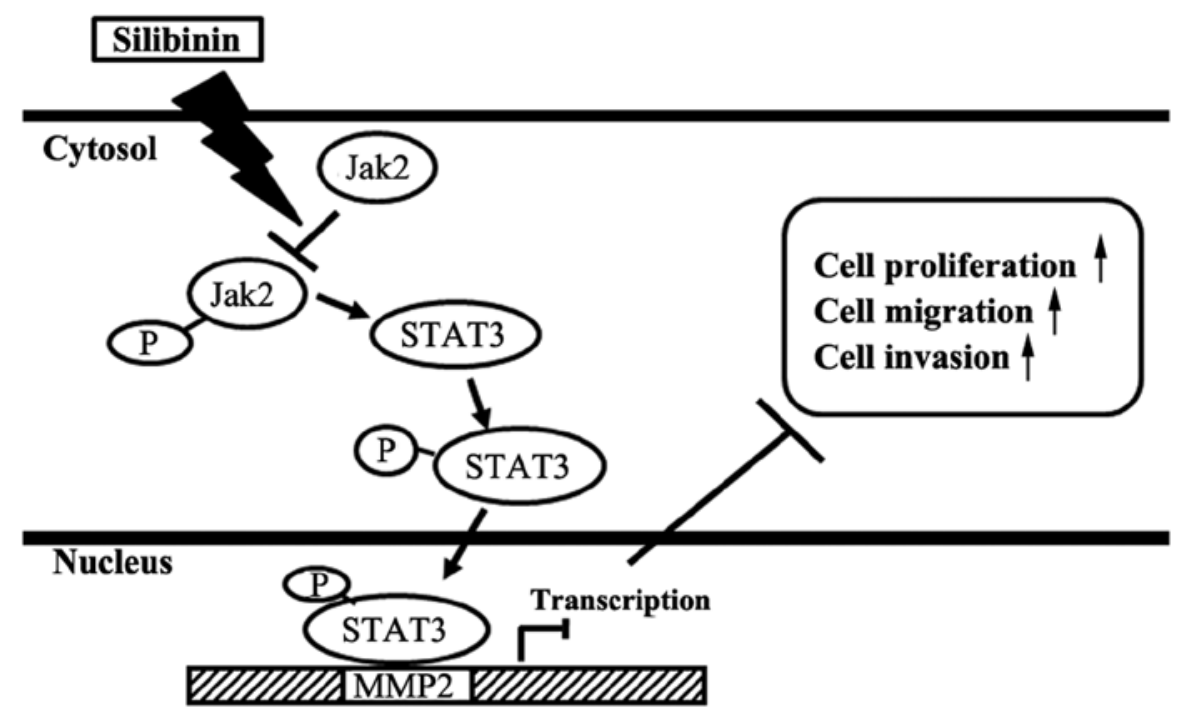

Figure 7. Schematic representation of the inhibition of invasive mechanisms provoked by silibinin in MDA-MB-231 cells. Silibinin inhibits Jak2 expression and phosphorylation, resulting, in turn, in the inhibition of STAT3 expression, phosphorylation, nuclear translocation, and DNA binding activity. Consequently, STAT3's down-stream targets are inhibited (including MMP2), resulting in reduced cell migration and invasion.

invasive capacity of TNBC cells (Fig. 6C). Compared with the control group, both $200 \mu \mathrm{M}$ silibinin-treated, and the STAT3 knock-down group, showed a 50\% reduction in migration rate (Fig. 6D). These results confirmed that silibinin inhibits cell migration and invasion by inhibiting STAT3 phosphorylation and MMP2 expression.

\section{Discussion}

Triple-negative breast cancer (TNBC) is an aggressive subtype of breast cancer that lacks endocrine receptor expression, and carries a mutated $\mathrm{p} 53$ gene. TNBCs are typified by their poor differentiation (attributed to rapid growth), are highly meta- 
static, and result in poor survival (31). While TNBCs express elevated levels of EGFR at their surface, targeted therapies to the EGFR does not improving overall survival of the patients, despite achieving a rapid shrinkage in tumor size (32). These findings have promoted our examination of the metastatic phenotype of TNBCs. In the present study, we used silibinin as an inhibitor of the metastatic potential of TNBC cells. It is already reported that silibinin has an inhibitory role in the proliferation, invasion, and migration of various cancer cell lines $(33,34)$. We found that silibinin also inhibited proliferation of the triple-negative breast cancer cell line MDA-MB-231, with an $\mathrm{IC}_{50}$ of $\sim 200 \mu \mathrm{M}$ for a treatment period of $24 \mathrm{~h}$ (Fig. 1). Even though this concentration is high in terms of physiologic level, dietary feeding of silibinin $0.5 \% \mathrm{w} / \mathrm{w}$ for a period of 7 weeks was shown to inhibit the growth of pancreatic cancer xenografts with no apparent changes in body weight or feeding habits (35). Similarly, the same $0.5 \% \mathrm{w} / \mathrm{w}$ concentration of silibinin inhibited the growth of ectopically implanted and established PC-3 tumor xenografts, without any gross sign of toxicity as monitored by feeding habits (i.e., appetite) and weight gain (36).

An understanding of the molecular mechanisms that underpin the anti-metastatic role of silibinin are essential if we are to develop new therapeutic strategies as well as drug combinations. For that, we checked the role of silibinin in the modulation of Jak2/STAT3 pathway in MDA-MB-231 cells. Jak2 is the receptor associated ligand-dependent tyrosine kinase responsible for phosphorylation of STAT3 $(6,7,9)$. Upon phosphorylation, STAT3 is activated and then regulates a broad range of downstream target genes, most related to malignant transformation and metastasis $(6,37,38)$. Silibinin at a concentration of $200 \mu \mathrm{M}$ inhibited Jak2 expression and phosphorylation, resulting in the inhibition of phosphorylation of its downstream substrate, STAT3 (Fig. 2A and C).

STAT3 phosphorylation at Y705 provokes its homo- or hetero-dimerization, and then nuclear translocation in order to bind gene-specific response elements in target gene promoters (i.e., MMP2) (39). The MMPs play an important role in various aspects of cancer such as gene expression, interaction with the ECM, and cell motility (40), all of which can affect the growth and differentiation of cells, their migration, and invasion $(11,12,40)$. In recent years, the targeting of MMPs has received considerable attention as a new treatment strategy with which to combat metastasis $(14,41)$. MMP2 is responsible for the migration and invasive phenotype of cancer cells by digesting the extracellular membrane and providing space for cells to migrate or invade. Analysis of the $M M P 2$ gene promoter sequence revealed a GAS element downstream of the transcription start site (Fig. 3B), with gel shift analyses indicating the DNA binding activity of STAT3 to the $M M P 2$ gene promoter, which could be inhibited by silibinin (Fig. 3C). Moreover, analyses at the mRNA and protein levels showed inhibition of both following exposure to silibinin (Fig. 4A and C). In order to confirm the role of STAT3 in the inhibition of MMP2 expression, we knockeddown STAT3 and then re-MMP2 expression levels. Knocking out of STAT3 effectively eliminated the expression of MMP2 (Fig. 5B).

Cell migration and invasion are the two major steps in the dissemination of cancers from their primary to secondary locations $(39,42)$. Accordingly, our aim was to inhibit the migration and invasive capacity of MDA-MB-231 cells using silibinin. Exposure to silibinin appears to inhibit cell migration and invasion in a dose- (Fig. 6A and C), and STAT3-dependent manner (Fig. 6C). Overall, the treatment with silibinin inhibited the gene specific transcriptional activation of MMP2 through the inhibition of Jak2 and STAT3 phosphorylation. This phosphorylation inhibition lead to the inhibition of Jak2/STAT3 pathway by blocking the STAT3 nuclear translocation, DNA-binding and resulted in the inhibition of proliferation, migration and invasion of TNBC cells (Fig. 7).

In conclusion, silibinin inhibits the cell proliferation of TNBC cells, together with their migration, and invasive potential. These results are consistent with our hypothesis that silibinin downregulates $M M P 2$ gene expression via Jak2/STAT3 pathway. These data lead us to suggest that silibinin be used as an experimental drug for the management of metastatic cancer, with promise shown in terms of increasing patient survival.

\section{Acknowledgements}

This study was supported by the Basic Science Research Program through the National Research Foundation of Korea (NRF); Ministry of Education (2013R1A1A2057942).

\section{References}

1. Cleator S, Heller W and Coombes RC: Triple-negative breast cancer: Therapeutic options. Lancet Oncol 8: 235-244, 2007.

2. Kuo WH, Chang YY, Lai LC, Tsai MH, Hsiao CK, Chang KJ and Chuang EY: Molecular characteristics and metastasis predictor genes of triple-negative breast cancer: A clinical study of triplenegative breast carcinomas. PLoS One 7: e45831, 2012.

3. Chen JQ and Russo J: ERalpha-negative and triple negative breast cancer: Molecular features and potential therapeutic approaches. Biochim Biophys Acta 1796: 162-175, 2009.

4. Garcia R, Bowman TL, Niu G, Yu H, Minton S, Muro-Cacho CA, Cox CE, Falcone R, Fairclough R, Parsons S, et al: Constitutive activation of Stat 3 by the Src and JAK tyrosine kinases participates in growth regulation of human breast carcinoma cells. Oncogene 20: 2499-2513, 2001.

5. Garcia R, Yu CL, Hudnall A, Catlett R, Nelson KL, Smithgall T, Fujita DJ, Ethier SP and Jove R: Constitutive activation of Stat3 in fibroblasts transformed by diverse oncoproteins and in breast carcinoma cells. Cell Growth Differ 8: 1267-1276, 1997.

6. Siveen KS, Sikka S, Surana R, Dai X, Zhang J, Kumar AP, Tan BK, Sethi G and Bishayee A: Targeting the STAT3 signaling pathway in cancer: Role of synthetic and natural inhibitors. Biochim Biophys Acta 1845: 136-154, 2014.

7. Imada K and Leonard WJ: The Jak-STAT pathway. Mol Immunol 37: 1-11, 2000.

8. Darnell JE Jr: STATs and gene regulation. Science 277: 1630-1635, 1997.

9. Thomas SJ, Snowden JA, Zeidler MP and Danson SJ: The role of JAK/STAT signalling in the pathogenesis, prognosis and treatment of solid tumours. Br J Cancer 113: 365-371, 2015.

10. Bowman T, Garcia R, Turkson J and Jove R: STATs in oncogenesis. Oncogene 19: 2474-2488, 2000

11. Rundhaug JE: Matrix metalloproteinases, angiogenesis, and cancer: commentary re: A. C. Lockhart et al., Reduction of wound angiogenesis in patients treated with BMS-275291, a broad spectrum matrix metalloproteinase inhibitor. Clin. Cancer Res., 9: 00-00, 2003. Clin Cancer Res 9: 551-554, 2003.

12. Verma RP and Hansch C: Matrix metalloproteinases (MMPs): Chemical-biological functions and (Q)SARs. Bioorg Med Chem 15: 2223-2268, 2007.

13. Visse R and Nagase H: Matrix metalloproteinases and tissue inhibitors of metalloproteinases: Structure, function, and biochemistry. Circ Res 92: 827-839, 2003. 
14. Brooks PC, Strömblad S, Sanders LC, von Schalscha TL, Aimes RT, Stetler-Stevenson WG, Quigley JP and Cheresh DA: Localization of matrix metalloproteinase MMP-2 to the surface of invasive cells by interaction with integrin $\alpha v \beta 3$. Cell 85: 683-693, 1996.

15. Rojiani MV, Alidina J, Esposito N and Rojiani AM: Expression of MMP-2 correlates with increased angiogenesis in CNS metastasis of lung carcinoma. Int J Clin Exp Pathol 3: 775-781, 2010.

16. Zheng H, Takahashi H, Murai Y, Cui Z, Nomoto K, Niwa H, Tsuneyama K and Takano Y: Expressions of MMP-2, MMP-9 and VEGF are closely linked to growth, invasion, metastasis and angiogenesis of gastric carcinoma. Anticancer Res 26A: 3579-3583, 2006.

17. Xie TX, Huang FJ, Aldape KD, Kang SH, Liu M, Gershenwald JE, Xie K, Sawaya R and Huang S: Activation of stat3 in human melanoma promotes brain metastasis. Cancer Res 66: 3188-3196, 2006.

18. Xie TX, Wei D, Liu M, Gao AC, Ali-Osman F, Sawaya R and Huang S: Stat 3 activation regulates the expression of matrix metalloproteinase-2 and tumor invasion and metastasis. Oncogene 23: 3550-3560, 2004.

19. Lee JW, Kwak HJ, Lee JJ, Kim YN, Lee JW, Park MJ, Jung SE, Hong SI, Lee JH and Lee JS: HSP27 regulates cell adhesion and invasion via modulation of focal adhesion kinase and MMP-2 expression. Eur J Cell Biol 87: 377-387, 2008.

20. Valenzuela A and Garrido A: Biochemical bases of the pharmacological action of the flavonoid silymarin and of its structural isomer silibinin. Biol Res 27: 105-112, 1994.

21. Singh RP and Agarwal R: Cosmeceuticals and silibinin. Clin Dermatol 27: 479-484, 2009.

22. Loguercio C and Festi D: Silybin and the liver: From basic research to clinical practice. World J Gastroenterol 17: 2288-2301, 2011.

23. Kosina P, Kren V, Gebhardt R, Grambal F, Ulrichová J and Walterová D: Antioxidant properties of silybin glycosides. Phytother Res 16 (Suppl 1): S33-S39, 2002.

24. Dehmlow C, Murawski N and de Groot H: Scavenging of reactive oxygen species and inhibition of arachidonic acid metabolism by silibinin in human cells. Life Sci 58: 1591-1600, 1996.

25. Tyagi AK, Singh RP, Agarwal C, Chan DC and Agarwal R: Silibinin strongly synergizes human prostate carcinoma DU145 cells to doxorubicin-induced growth Inhibition, $\mathrm{G}_{2}-\mathrm{M}$ arrest, and apoptosis. Clin Cancer Res 8: 3512-3519, 2002.

26. AgarwalC,Singh RP,Dhanalakshmi S, Tyagi AK, Tecklenburg M, Sclafani RA and Agarwal R: Silibinin upregulates the expression of cyclin-dependent kinase inhibitors and causes cell cycle arrest and apoptosis in human colon carcinoma HT-29 cells. Oncogene 22: 8271-8282, 2003.

27. Bosch-Barrera $\mathbf{J}$ and Menendez JA: Silibinin and STAT3: A natural way of targeting transcription factors for cancer therapy. Cancer Treat Rev 41: 540-546, 2015.

28. Tyagi A, Agarwal C, Dwyer-Nield LD, Singh RP, Malkinson AM and Agarwal R: Silibinin modulates TNF- $\alpha$ and IFN- $\gamma$ mediated signaling to regulate COX2 and iNOS expression in tumorigenic mouse lung epithelial LM2 cells. Mol Carcinog 51: 832-842, 2012.
29. Lim EJ, Hong DY, Park JH, Joung YH, Darvin P, Kim SY, Na YM, Hwang TS, Ye SK, Moon ES, et al: Methylsulfonylmethane suppresses breast cancer growth by down-regulating STAT3 and STAT5b pathways. PLoS One 7: e33361, 2012.

30. Björklund $\mathrm{M}$ and Koivunen E: Gelatinase-mediated migration and invasion of cancer cells. Biochim Biophys Acta 1755: 37-69, 2005.

31. Bauer KR, Brown M, Cress RD, Parise CA and Caggiano V: Descriptive analysis of estrogen receptor (ER)-negative, progesterone receptor (PR)-negative, and HER2-negative invasive breast cancer, the so-called triple-negative phenotype: A population-based study from the California cancer Registry. Cancer 109: 1721-1728, 2007.

32. Dent R, Hanna WM, Trudeau M, Rawlinson E, Sun P and Narod SA: Pattern of metastatic spread in triple-negative breast cancer. Breast Cancer Res Treat 115: 423-428, 2009.

33. Gluz O, Liedtke C, Gottschalk N, Pusztai L, Nitz U and Harbeck N: Triple-negative breast cancer - current status and future directions. Ann Oncol 20: 1913-1927, 2009.

34. Chu SC, Chiou HL, Chen PN, Yang SF and Hsieh YS: Silibinin inhibits the invasion of human lung cancer cells via decreased productions of urokinase-plasminogen activator and matrix metalloproteinase-2. Mol Carcinog 40: 143-149, 2004.

35. Nambiar D, Prajapati V, Agarwal R and Singh RP: In vitro and in vivo anticancer efficacy of silibinin against human pancreatic cancer BxPC-3 and PANC-1 cells. Cancer Lett 334: 109-117, 2013.

36. Singh RP, Deep G, Blouin MJ, Pollak MN and Agarwal R: Silibinin suppresses in vivo growth of human prostate carcinoma PC-3 tumor xenograft. Carcinogenesis 28: 2567-2574, 2007.

37. Yu H, Lee H, Herrmann A, Buettner R and Jove R: Revisiting STAT3 signalling in cancer: New and unexpected biological functions. Nat Rev Cancer 14: 736-746, 2014.

38. Darvin P, Joung YH, Sp N, Kang DY, Byun HJ, Hwang DY, Cho KH, Park KD, Lee HK and Yang YM: Sorghum polyphenol suppresses the growth as well as metastasis of colon cancer xenografts through co-targeting jak2/STAT3 and PI3K/Akt/mTOR pathways. J Funct Foods 15: 193-206, 2015.

39. Darvin P, Baeg SJ, Joung YH, Sp N, Kang DY, Byun HJ, Park JU and Yang YM: Tannic acid inhibits the Jak2/STAT3 pathway and induces G1/S arrest and mitochondrial apoptosis in YD-38 gingival cancer cells. Int J Oncol 47: 1111-1120, 2015.

40. Egeblad M and Werb Z: New functions for the matrix metalloproteinases in cancer progression. Nat Rev Cancer 2: 161-174, 2002.

41. Bauvois B: New facets of matrix metalloproteinases MMP-2 and MMP-9 as cell surface transducers: Outside-in signaling and relationship to tumor progression. Biochim Biophys Acta 1825: 29-36, 2012.

42. Yilmaz M and Christofori G: EMT, the cytoskeleton, and cancer cell invasion. Cancer Metastasis Rev 28: 15-33, 2009. 